\title{
Surface cleaning and corrosion protection using plasma technology
}

\author{
T. Török, P. Urbán and G. Lassú
}

University of Miskolc Institute of Metallurgy and Foundry Engineering, Chemical Metallurgy and Surface Techniques, Miskolc-Egyetemvaros, 3515 Miskolc, Hungary E-mail:fektt@uni-miskolc.hu

\section{Abstract}

Nowadays plasma techniques are getting more and more involved in production technologies because the traditional chemical treatments are sometimes less feasible and/or environmentally harmful. Besides the plasma pre-treatments, the plasma technology can also be utilized to develop thin protective layers. Day by day new techniques come into sight, so the categorization and review of them is an important task, which was the primary aim in this paper by trying to make an account on the most up-to-date ones. In this way, some important characteristic features and major advantages are presented here for the plasma treatment of plastic surfaces under ambient atmosphere, ultrafine surface cleaning with low-pressure plasma sources, and an example for the RF-PACVD deposition of protective and highly corrosion resistant thin glassy layers by plasma polymerization of HMDSO precursors. Envisaged future utilization of a small-scale atmospheric pressure plasma (APP) jet system installed in the Laboratory of Surface Techniques at University of Miskolc is also discussed.

Keywords: plasma, ultrafine plasma cleaning, plasma polymerization, protective films, HMDSO, corrosion testing, laboratory APP jet.

Received: November 17, 2014; revised: January 20, $2015 . \quad$ doi: $10.17675 / 2305-6894-2015-4-2-116-124$

\section{Introduction}

Surface cleaning and surface pretreatment are among the most basic operations of coating technologies. Besides the oily or greasy organic contaminants that commonly adhere to metallic surfaces, special attention should be paid to the elimination of native oxide/hydroxide compound layers and corrosion products that almost inevitably evolve on the surface - due to exposure to ambient air - of certain metal species and alloys that are particularly liable to corrosion.

As it is well-known, proven and widely used methods are available to clear away thick contaminant layers and corrosion products from surfaces [1]. There is, however, a growing need for the removal of trace quantities of residual contamination from surfaces, in short, for ultrafine cleaning. This can be executed with rapidly emerging new surface technologies like plasma treatments with partially ionized (plasma) gases [2], and the surface cleanliness can be monitored by several sophisticated surface analytical techniques, among which a newly acquired glow discharge optical emission spectrometer (GD-OES) 
can also be mentioned, a which is a suitable tool to check and evaluate pre- and posttreatment surface cleanliness and surface activation states as well as elementary depth profiles down to several tenths micrometers [3].

The aim of this study is to provide a brief overview of surface treatments with plasma gases and to propose novel applications where the thin film coatings deposited on plasmacleaned surfaces are ascribed additional functionalities, such as advanced corrosion protection.

Some fractions of adsorbed, loosely adherent volatile substances (e.g. surface moisture) can be released by creating reduced pressure conditions e.g. by placing the object in a vacuum chamber. This principle is used for the removal of physisorbed water from substrates (vacuum drying) [4]. On the other hand, more "drastic" interventions are needed to mobilize strongly bound, chemisorbed materials or to clear away native oxide films from metallic surfaces. The functional characteristics of traditional wet-chemical cleaning methods and progressive plasma technologies are compared in Table 1 [5].

Table 1. Comparison of plasma processes and wet chemical processes.

Plasma Processes

Processes are easily controllable through RF, DC or microwave power, time, gas, pressure and type.

No residues remain.

Wet Chemical Processes

Processes are very sensitive to time and chemical concentrations.

Reliability requires removing or neutralizing residues, which may require multiple cleaning steps.

Waste products are generally in gaseous form and can generally be liberated directly to the atmosphere after passing through the vacuum pumps and filters (if needed).
Most of the gases used have no toxicity.
There is a high volume of liquid waste, which requires expensive treatment and government permits.

Most of the solvents and acids used are extremely hazardous.

Surface cleaning technologies are certainly of diverse nature, depending on the material quality and surface characteristics of the cleaned product. The typical layer structure of slightly contaminated products and materials that commonly occur in ultrafine and plasma cleaning are illustrated in Figure 1 [5].

\section{Plasma treatment of plastic surfaces under ambient atmosphere}

As opposed to the metallic and inorganic materials (glasses, ceramics) presented in Figure 1, plastics exhibit radically different structural properties and surface behavior. The treatment of plastic/polymer surfaces prior to painting (grinding, polishing, roughening, degreasing, dusting) may demand unique, specific solutions [6]. Precision cleaning by dry ice blasting (i.e., solid-phase $\mathrm{CO}_{2}$ ejection) is often complemented with plasma gas processes for the efficient removal of trace organic contaminants. 

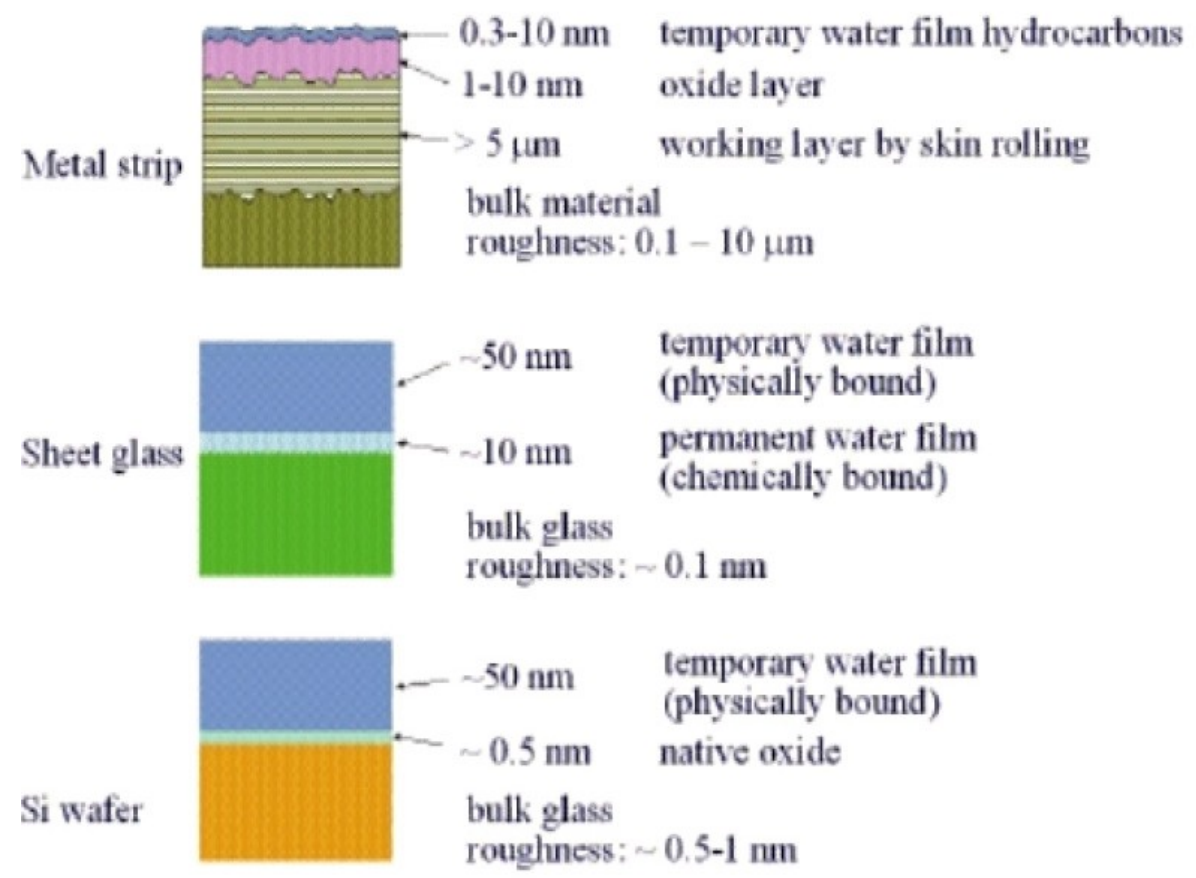

Figure 1. Surface structure and typical surface (nano) contamination of some materials [5].

Workpieces with complex surface geometries are best to be handled in low-pressure plasma chambers in a non-continuous working mode, which allows for different plasma gas compositions and plasma mixing with proper reactive components. Whereas atmospheric pressure plasma (APP) systems can be effectively implemented in continuous production lines for the surface treatment/cleaning of single plastic sheets and plain polymer products (with simple geometries). Meanwhile, plasma impingement induces slight chemical reactions yielding active radicals on the polymer surfaces. Due to ion energy impingement, higher energy levels for the substrates are obtained, leading to the modification of surface states - thus to substantially increased wettability. This type of surface activation is definitely preferable for a number of coating, printing, bonding or sealing technologies. Practical applications of atmospheric plasma treatments have been recently reported by Melamies [7]. For the demonstration of APP treatment efficiency, the adhesion test results of three types of polymers bound with two component epoxy resin adhesive are presented in Figure 2 [7].

The improved wettability of plasma-treated polymer surfaces combines particularly well with water-based paints that are extensively used in the automotive industry and other economic key sectors. With the development of new-generation primer-free paints for vehicle manufacturing, plasma treatments are expected to attain an increasingly important role. 


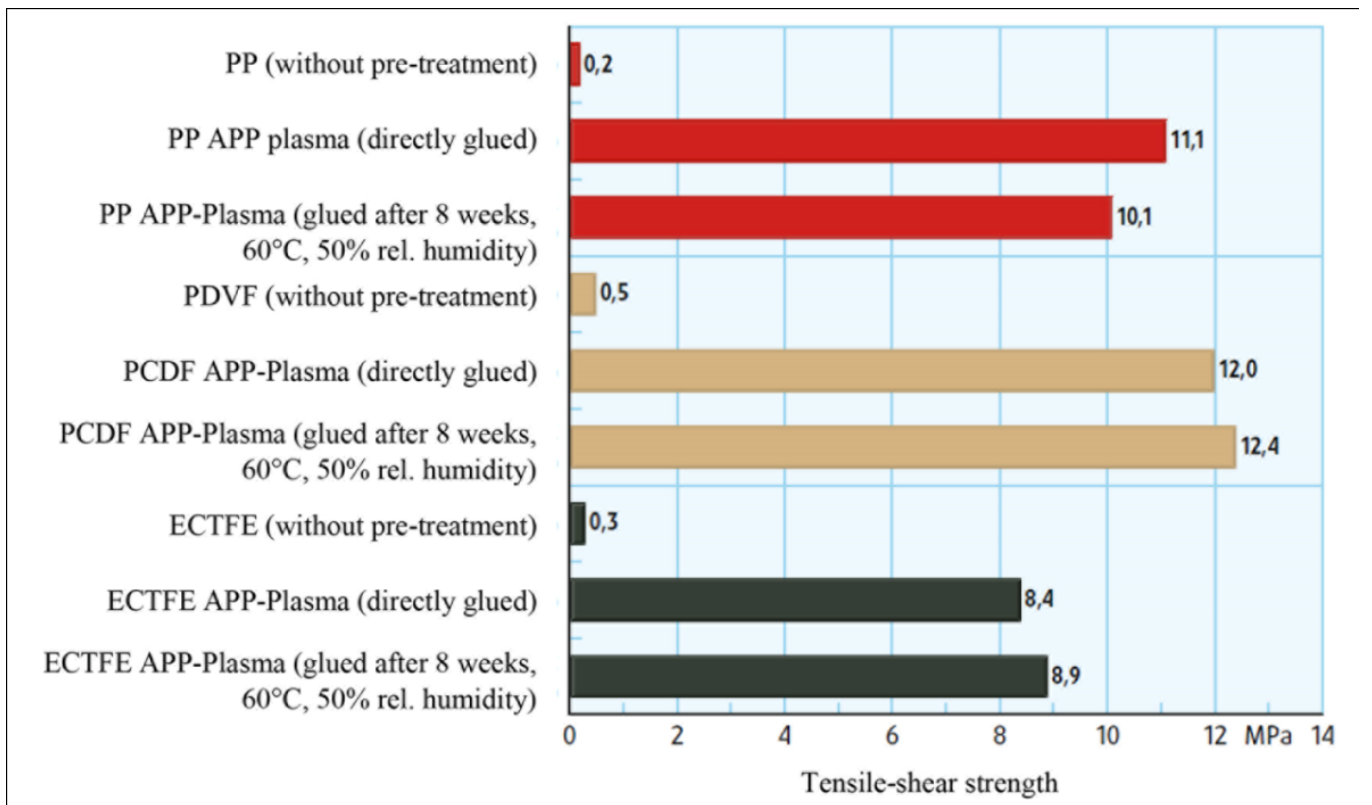

Figure 2. Tensile test results of laminated polymers. The long-term behavior of distinctive plasma-activated polymers: PP - Polypropylene, PVDF - Polyvinylidene fluoride, ECTFE a copolymer of ethylene and chlorotrifluoroethylene [7]

\section{Surface cleaning with low-pressure plasma sources}

Surface cleaning with low-pressure (non-atmospheric) plasma sources are for long successfully applied at semiconductor technologies [8].

Prior to thin film preparation through low-pressure chemical vapor deposition, the substrates are normally pretreated by ultrasonic and water cleaning. Once the objects are placed in the evacuated vacuum chamber, they undergo sputtering (plasma etching by glow discharge), whereby absorbed water and oxygen molecules get removed from the substrate surface and the adhesive properties of the sputtered layer are enhanced. Coating adhesion, however, can be most effectively facilitated if an ultrafine layer (up to a few atomic diameters thickness) of the bulk material is also stripped (i.e., physically abraded) together with the absorbed (contaminant) layer. In the manufacturing of semi-conductive layers, the surfaces obtained this way are called "atomically pure". The described method is, in fact, considered a special type of plasma cleaning which involves the physical etching of the treated surface via the bombardment of the surface with ions, electrons and other particles (molecules, radicals) from the plasma gas. Plasma cleaning by sputtering is a widely used alternative to chemical etching in the semiconductor industry. The two treatments are functionally the same, yet yield somewhat different surface topographies [8].

Besides semiconductor production and the microelectronics sector, a growing range of industrial operations (e.g., metal processing, the production of fittings or component parts, the cleaning of solderable metal parts, etc.) extensively rely on plasma cleaning processes assisted by low-pressure supply sources like direct current voltage (DC), 
radiofrequency $(\mathrm{RF})$, microwaves or other sources of glow discharge. A peculiar example of plasma applications is the surface decontamination of noble metals reported by Fuchs [9], who examined oxygen and hydrogen plasmas at 0.2 and 0.7 mbar pressures to clean the surfaces of golden and platinum-iridium specimens in high-frequency $(40 \mathrm{kHz} / 1 \mathrm{~kW})$ plasma systems. For the removal of organic contaminants and surface oxide layers, hydrogen plasma was found slightly more effective (than oxygen), which Fuchs even proposed as a viable tool for the cleaning of the International Prototype Kilogram (i.e., standard Pt-Ir alloy cylinder in Sévres, France).

\section{Protective film deposition by plasma polymerization}

For centuries, organic coatings, paints and varnishes have been used, providing permanent or temporary protection to various metals against severe or corrosive environments. Recently, however, even certain inhibitors are applied for corrosion protection of metals in an innovative way, namely, in combination with advanced plasma technologies $[10,11]$.

Lately, thin polymer films from chemically synthesized precursor substances (monomers) have been also introduced as functional/coating materials. The polymerization of monomer molecules - like hexamethyldisiloxane (HMDSO), which yields glassy, ultrafine layers - can be effectively controlled via radiofrequency (RF) plasma-assisted chemical vapor deposition techniques (RF-assisted plasma activation). For this purpose, protective thin films $(\sim 500 \mathrm{~nm})$ with a defective $\mathrm{Si}-\mathrm{O}-\mathrm{Si}$ chemical structure have been deposited on bell metal samples $(78 \% \mathrm{Cu}-22 \% \mathrm{Sn})$ in a low-pressure reactor chamber (Figure 3) using $\mathrm{Ar} / \mathrm{HDMSO} / \mathrm{O}_{2}$ plasma gas atmosphere [12].

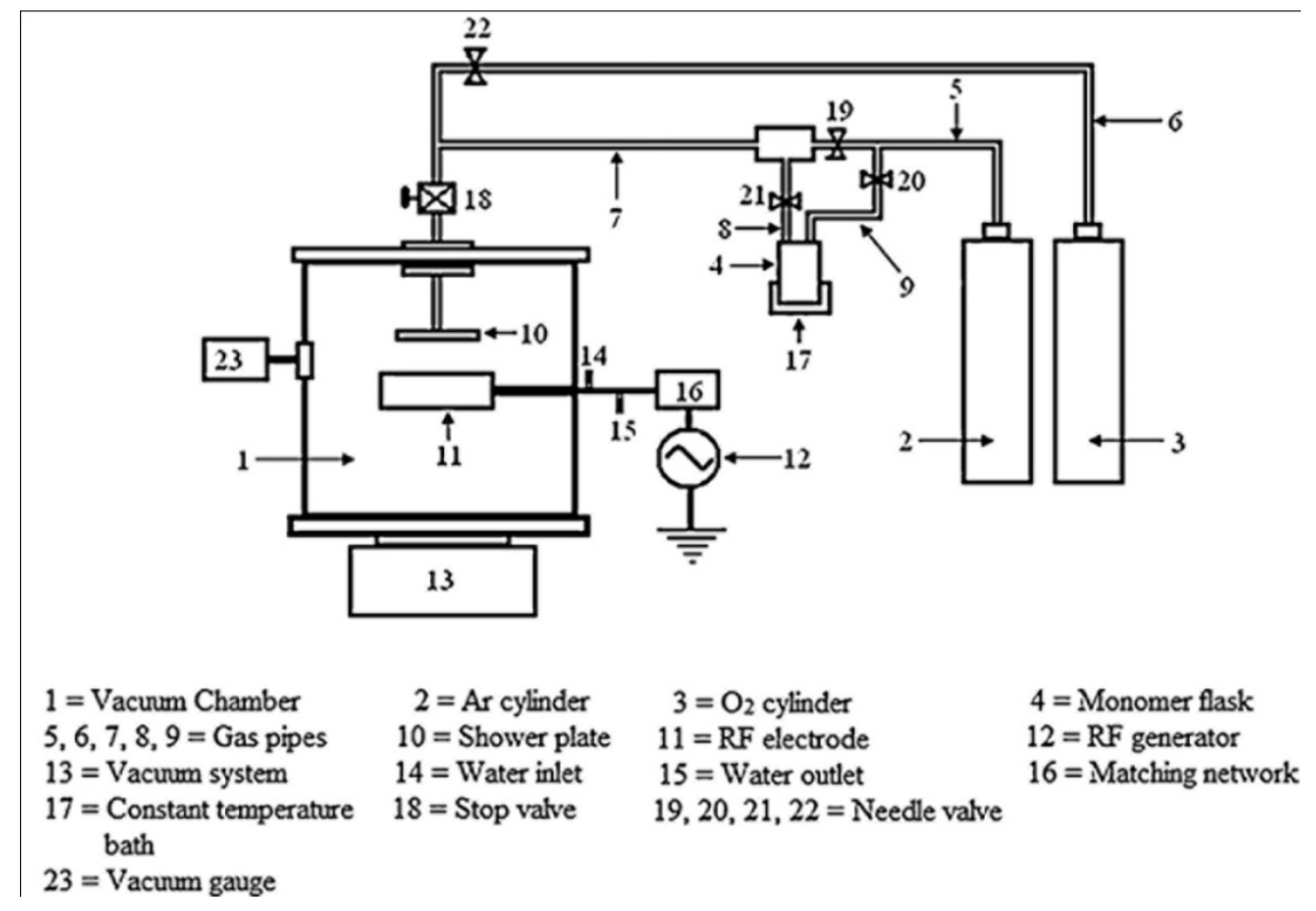

Figure 3. Schematic diagram of the experimental setup of the RF-PACVD (radiofrequencyinduced plasma-assisted chemical vapor deposition) plasma reactor [12]. 
Out of the $\mathrm{SiH}, \mathrm{CH}, \mathrm{SiO}, \mathrm{CO}, \mathrm{H}_{2}$ and $\mathrm{H}$ species detected in the $\mathrm{Ar} / \mathrm{HDMSO} / \mathrm{O}_{2}$ plasma discharge, trace amounts of atomic $\mathrm{C}(\sim 2-15 \%)$ got co-deposited and incorporated in the $\mathrm{Si}-\mathrm{O}-\mathrm{Si}$ structure as a function of the negative 'floating potential' of the substrate (i.e., the ion energy impinging on the substrate) (Figure 4), which substantially changed the hardness, elastic modulus, surface energy and wettability of the deposited polymeric film layer (Fig 5).

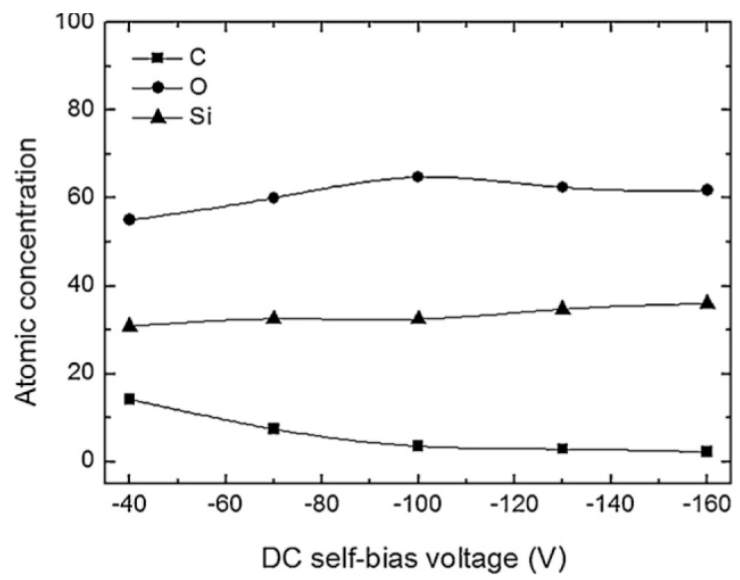

Figure 4. Variation of atomic composition (elemental components $\mathrm{Si}, \mathrm{O}$ and $\mathrm{C}$ in pp-HMDSO layers deposited by plasma polymerization) as a function of DC self-bias voltage [12].
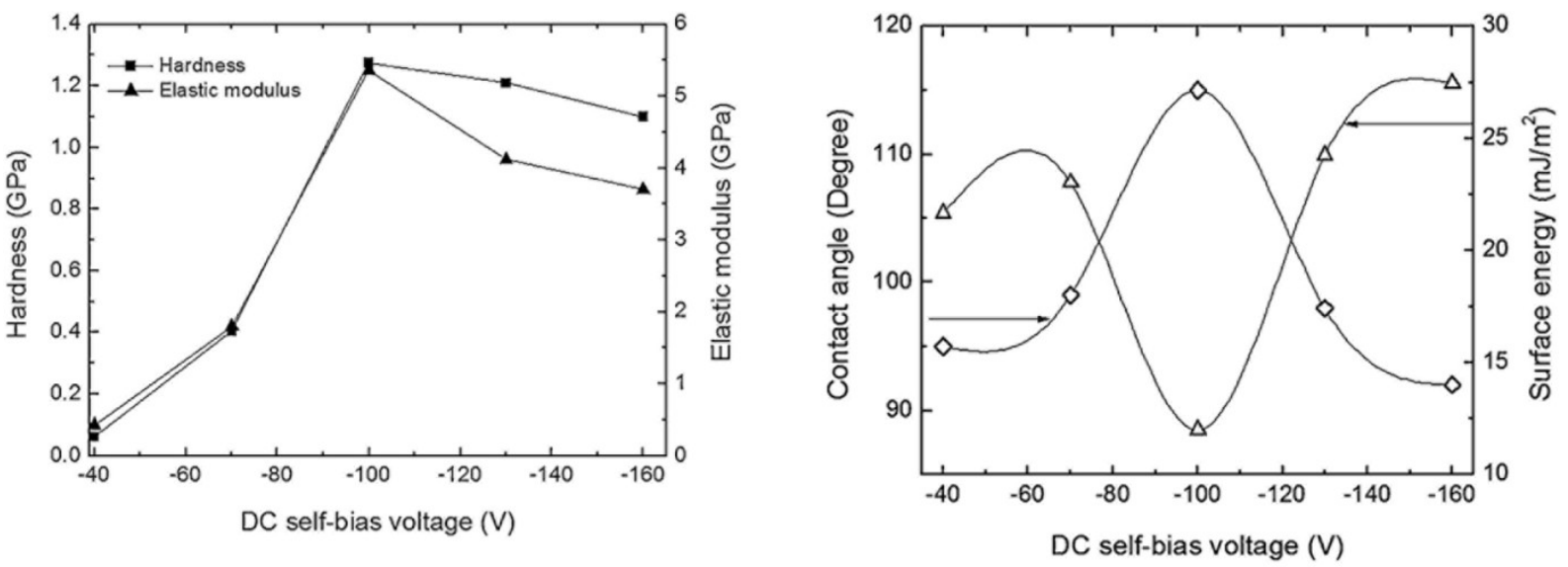

Figure 5. Variation of hardness, elastic modulus, water contact angle and surface energies (of the deposited pp-HMDSO films) as a function of DC self-bias voltage [12].

Prior to deposition, the reaction chamber was put under vacuum (i.e., evacuated to a base pressure of $0.001 \mathrm{mbar}$ ), and the substrate surfaces were cleaned in argon plasma (Ar flow volume: $5 \mathrm{~cm}^{3}$ per min; flow rate: $5 \mathrm{sccm}$; DC self-bias voltage: $-100 \mathrm{~V}$ ). The deposition process was carried out at a working pressure of 0.16 mbar at a DC self-bias voltage range of $-40 \mathrm{~V}$ to $-160 \mathrm{~V}$. Argon and oxygen gas was supplied at 5 and $10 \mathrm{sccm}$, respectively. HMDSO (precursor) monomer flow was simultaneously injected at a flow rate of $35 \mathrm{sccm}$. RF-assisted plasma-polymerized HMDSO film deposition was maintained for $30 \mathrm{~min}$ at each voltage level throughout the experiments. 
The deposited thin polymer film revealed the highest oxygen content at a DC self-bias voltage of $-100 \mathrm{~V}$ (Figure 4), where the layer exhibited the most favorable protective performance in terms of functional use (least defective chemical structure, highest inorganic character, maximum hardness and elastic modulus, smooth surface structure, enhanced water repellency) (Figure 5).

The corrosion resistance behavior of the pp-HDMSO film-coated bell metal samples was investigated by standard copper acetic acid salt (CASS) test (ASTM-B-368), using a homogeneous $\mathrm{NaCl}-\mathrm{CuCl}$ solution $\left(0.026 \% \mathrm{CuCl} \cdot \mathrm{H}_{2} \mathrm{O}+5 \% \mathrm{NaCl} ; \mathrm{pH}=3.1\right)$, and immersing one-third (1/3rd) of the films inside the solution for a total observation time of $60 \mathrm{~h}$. The surface of the virgin bell metal (reference sample) soon turned black, while the sample with pp-HMDSO film deposited at DC self-bias voltage of $-100 \mathrm{~V}$ showed no signs of color change, cracking or peeling off even after several hours of testing (Figure 6).

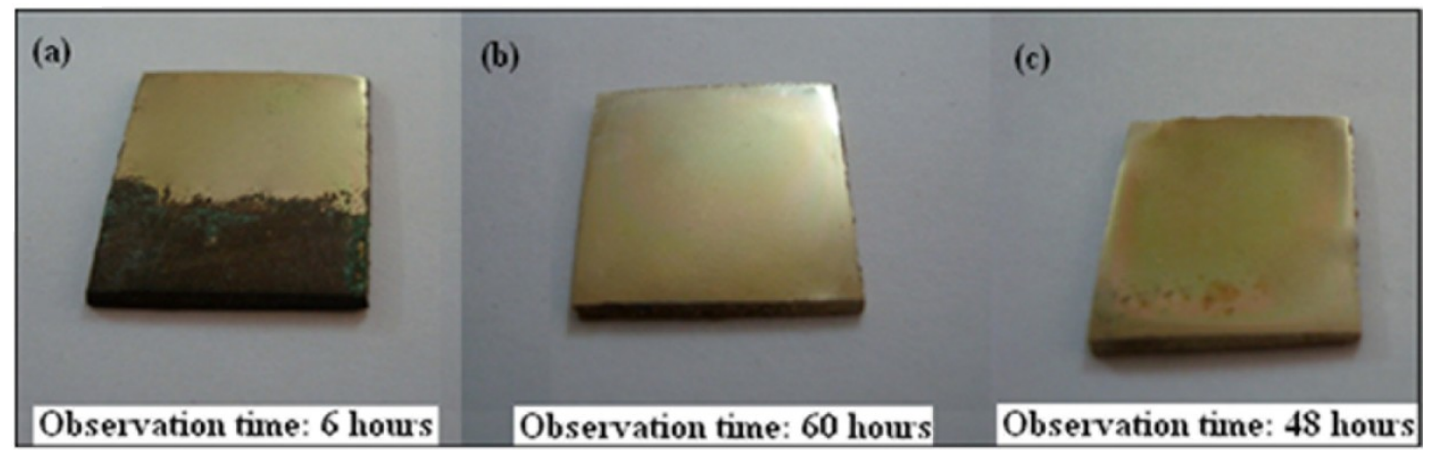

Figure 6. Optical images showing corroded surfaces of $a$ ) virgin bell metal and pp-HMDSO films deposited at DC self-bias voltages of $b$ ) $-100 \mathrm{~V}$ and $c$ ) $-130 \mathrm{~V}$ [12].

Based on the prime characteristics of plasma treatments and plasma-activated coating technologies briefly presented above and on the experimental results [12], it can be concluded that plasma polymerization allows for the manufacturing of high-quality protective coatings with excellent corrosion resistance. As regards the demonstrated RFPAVCD system (used for the described treatment), the low-pressure working mode required for smooth operation would potentially limit the large-scale applicability of the method.

In this respect, enticing are the results obtained from a series of recent experiments which targeted the deposition of similar pp-HMDSO protective layers on $\mathrm{Cu}$ substrate surfaces under atmospheric pressure [13]. Our department of Chemical Metallurgy and Surface Techniques of the University of Miskolc plans to conduct research of the latter type with a small-scale atmospheric pressure plasma (APP) jet system installed in our Laboratory of Surface Techniques. This equipment allows for plasma treatment operations like:

- surface pretreatment prior to adhesive bonding, sticking, painting or printing

- ultrafine cleaning

- polymer-activation 
- deposition of hydrophobic polymer layers (for enhanced corrosion protection and scratch-resistance)

- deposition of water-repellant polymer layers (for enhanced adhesion properties)

- thin film deposition for the control of solid phase diffusion

- surface hardening.

Out of the various industries that benefit from APP plasma treatment techniques, the following ones are worth mentioning:

- automotive industry, vehicle manufacturing

- electronics and microelectronics industry

- packaging industry

- durable consumer goods production

- medical and pharmaceutical products

- textile industry

- renewable energy sector (solar collectors, solar cell systems)

- aeronautics industry

- furniture industry.

The laboratory APP jet system is designed for systematic, meticulous laboratory investigations, which enable professional users to analyze and evaluate the effects of surface treatments applied on various substrates with different operational parameters.

\section{Acknowledgement}

The described work was carried out as part of the TÁMOP-4.2.2.A-11/1/KONV-20120019 project in the framework of the New Széchenyi Plan. The realization of this project is supported by the European Union, co-financed by the European Social Fund. It was partially carried out in the framework of the Center of Applied Materials Science and Nanotechnology at the University of Miskolc.

\section{References}

1. T. Török, Modern metal surface treatment and waste management practices, Phare CD-textbook, University of Miskolc, 2004 (in Hungarian).

2. C. Tendero, C. Tixier, P. Tristant, J. Desmaison and P. Leprince, Spectrochim. Acta, Part B, 2006, 61, 2 .

3. T. Török, G. Szirmai and V. Orosz, Korróziós Figyelö, 2011, 51, no. 5, 99 (in Hungarian).

4. M. Örvös, Diffusion processes and equipment, BMGE, Budapest, 2006 (in Hungarian).

5. A. Belkind and S. Gersham, Plasma Cleaning of Surfaces 1-11, Vacuum Technology \& Coating, Ed. by Jinghong Vacuum Thin Film (Shenzen) Co. Ltd., 2008. 
6. D. Schulz, Painting of Plastics effectively, TechMonitor 2012, http://www.techmonitor.hu/termek-megoldas/muanyagok-festese-hatekonyan2012/11/27.

7. I. A. Melamies, Kunststoffe, 2011, no. 10, 163.

8. G. Vágó, Plasma techniques, Report, KFKI, 2008 (in Hungarian).

9. P. Fuchs, Appl. Surf. Sci., 2009, 256, 1382.

10. A. M. Dorfman, A. M. Lyakhovich, V. I. Povstugar and S. G. Bystrov, Zashch. Met., 2000, 36, no. 3, 291 (in Russian).

11. S. G. Bystrov, A. M. Dorfman, A. M. Lyakhovich and V. I. Povstugar, Poverkhnost'. Rentgenovskie, sinkhrotronnye $i$ neitronnye issledovaniya, 2000, 40, no. 11 (in Russian).

12. A. J. Choudhury, S. A. Barve, J. Chutia, A. R. Pal, R. Kishore, Jagannath, M. Pande and D. S. Patil, Appl. Surf. Sci., 2011, 257, 8469.

13. C. Regula, J. Ihde, U. Lommatzsch and R. Wilken, Surf. Coat. Technol., 2011, 205, 355. 